Chapman University

Chapman University Digital Commons

$1-6-2021$

Case Conceptualization as an Alternative to Educationally Related Mental Health Assessments

Michael R. Hass

Zack Maupin

Michael Doria

Follow this and additional works at: https://digitalcommons.chapman.edu/education_articles

Part of the Educational Assessment, Evaluation, and Research Commons, Educational Psychology Commons, and the School Psychology Commons 


\section{Case Conceptualization as an Alternative to Educationally Related Mental Health}

Assessments

\section{Comments}

This is a pre-copy-editing, author-produced PDF of an article accepted for publication in Contemporary School Psychology in 2021 following peer review. The final publication may differ and is available at Springer via https://doi.org/10.1007/s40688-020-00349-y.

A free-to-read copy of the final published article is available here.

\section{Copyright}

California Association of School Psychologists 


\title{
Case Conceptualization as an Alternative to Educationally Related Mental Health Assessments
}

\author{
Michael R. Hass, Ph.D. \\ Zack Maupin, Ed.S. \\ Michael Doria, Ed.S. \\ Attallah College of Educational Studies \\ Chapman University
}

Accepted for publication in Contempoary School Psychology December 22, 2020 


\begin{abstract}
School psychologists play an essential role in the provision of school-based mental health services yet continue to spend the majority of their time conducting psychoeducational assessments. In California, changes in law regarding the provision of mental health services have increased the tension around the role of school psychologists and led to models for determining the need for mental health services that are inefficient and present a potential barrier to students receiving services in a timely manner. The paper proposes case conceptualization as a more useful and efficient approach, than traditional assessment processes for determining students' mental needs and writing goals.
\end{abstract}

Keywords: Assessment, Mental health, Case conceptualization 
A consensus has emerged over the last several years that about $20 \%$ of children and adolescents have a diagnosable mental health condition that requires treatment (Adelman and Taylor, 2012). Even this figure is likely an underestimate of the number of children who need mental health supports. For example, there are potentially many more students who have socalled "subclinical" conditions. Although these conditions may not be severe enough to meet the criteria for a formal diagnosis, they are still serious enough to cause significant difficulties in coping with the academic and social demands of schools. Schools have become one of the primary settings for addressing these needs, with some literature suggesting that as many as $70 \%$ of the students who obtain services receive them in schools (Burns et al., 1995; Wiley \& Corey, 2013). Given this, schools and school personnel such as school psychologists are a critical component to meeting the needs of these children and providing access to high-quality mental health care (Committee on School Health, 2004).

The provision of mental health services is well within the scope of practice of school psychologists. For example, in the recently updated Professional Standards of the National Association of School Psychologists (NASP), Domain 4: Mental and Behavioral Health Services and Interventions (NASP, 2020) states:

School psychologists understand the biological, cultural, developmental, and social influences on mental and behavioral health, behavioral and emotional impacts on learning, and evidence-based strategies to promote social-emotional functioning. School psychologists, in collaboration with others, design, implement, and evaluate services that promote resilience and positive behavior, support socialization and adaptive skills, and enhance mental and behavioral health. 
NASP provides examples of the activities that might be included under this domain to guide school psychologists in the kinds of mental health services they can provide in schools (see Table 1).

\section{Table 1}

\section{NASP Domain 4 Guidelines for School Psychologists Providing Mental Health Services}

- Recognizing risk and protective factors and utilizing data and assessment to help students develop socially and emotionally.

- Integrating behavioral supports and mental health services with academic and learning goals for students.

- Understanding the influence of trauma on social, emotional, and behavioral functioning while collaborating to support student learning and behavior.

- Using culturally responsible and developmentally appropriate methods to assess, identify, and support students' mental and behavioral health.

- Upholding systematic decision-making that considers the antecedents, consequences, functions, and causes of behavioral difficulties.

- Maximizing acceptable interventions while upholding their fidelity throughout stages of development, implementation, and evaluation.

- Developing and implementing behavior change programs at the individual, group, classroom, and school- or district-wide levels that consider ecological and behavioral approaches for managing student behavior.

- Evaluating implementation and outcomes of evidence-based mental and behavioral health interventions for individual students.

- Promoting effective collaborations between home, school, and community agencies to promote mental and behavioral health supports. 
Despite the need for more school-based mental health services (SBMHS) and the potential for school psychologists to help meet these needs, for most school psychologists, dayto-day practice is taken up with assessment and classification of students (Merrell et al. 2006). More specifically, survey data suggest that school psychologists spend over half their time conducting psychoeducational assessments and only about $20 \%$ of their time providing direct interventions such as SBMHS (Fagan \& Wise, 2000). This dilemma of "too much testing" has long been recognized as a barrier to school psychologists having more time to provide direct services to students (Castillo et al., 2016). In a recent dissertation study, Petereit (2020) found testing to be a common obstacle to school psychologists implementing the breath of services suggested by the NASP practice domains. In this survey, when school psychologists considered their ideal roles compared to their actual responsibilities, their reported discrepancy for NASP's Domain 4 was nearly twice as large as other domains they indicated wanting more time for.

This tension between what school psychologists can do and what they actually do has played out vividly in California over the last ten years. For 27 years, Assembly Bill (AB) 3632 granted California public schools an exception to the requirement to directly provide mental health services for students with disabilities. Instead, AB 3632 had mandated that California school districts and county mental health agencies collaborate to provide mental health services for students with disabilities rather than school districts. In effect, students with disabilities were offered outsourced mental health treatment as "related services" by county mental health agencies rather than school staff. On June 30, 2011, California's AB 114 rendered AB 3632 inoperative and made school districts solely responsible for ensuring that students receive what the bill described as: 
"...educationally related mental health services, including out-of-home residential services for emotionally disturbed pupils, required by an individualized education program pursuant to the federal IDEA of 2004 (20 U.S.C. $§ 1400$ et esq.)."

Since AB 114, Local Educational Agencies (LEA's) in California have been under pressure to quickly develop policies to fill the gaps left by the withdrawal of county mental health agencies. Because of limited guidance provided by the state department of education and little prior experience with organizing mental health services, LEA's have created a hodgepodge of different policies and procedures related to the assessment, delivery, and distribution of mental health services. These policies have included continuing to outsource mental health services to community agencies or hiring licensed professionals who are not school psychologists or school counselors to perform mental health assessments and provide services.

Given this diverse and uncertain landscape, California school psychologists face various procedures for determining the need for mental health services. Unfortunately, these procedures have often retained the requirement of additional mental health assessments beyond assessments previously done by the LEA. These secondary mental health assessments are time-consuming and frequently redundant with prior psychoeducational evaluations because they often repeat social-emotional assessment procedures used in previous recent evaluations. In the process of pursuing mental health services through special education, these add-on assessments and their procedural timelines pose as possible barriers forcing students to wait up to 60 days before school districts begin to provide the needed services. This time lag is especially problematic when LEAs have completed an initial or triennial evaluation and identified a mental health need. In many school districts in California, these assessments are conducted by personnel other than those who did the initial or triennial evaluations. This introduction of another 60-day timeline 
and other personnel can complicate the process of determining a mental health need and providing students needed services and is unnecessarily burdensome for families.

We recognize that assessments to determine the need for mental health services may occur outside of initial or triennial evaluations. We argue that even in these cases, mental health assessments are within the purview of school psychologists and do not constitute a different kind of evaluation that requires personnel with different backgrounds. We also understand that many students outside of special education need mental health services. Because this paper is, in part, a response to changes in law and policy in California, our focus is on using case conceptualization in the context of mental health evaluations for special education services.

We argue that the procedures that have emerged post AB 114, including extensive mental health evaluations with new 60-day timelines, create unnecessary barriers to accessing treatment. In this paper, we argue for a streamlined, yet, legally defensible, case conceptualization approach to identifying students' mental health needs and determining appropriate related services. We also argue that this model will remove barriers to receiving service and provide an efficient, evidence-based, and legally sound approach to providing mental health-related services to students receiving special education support.

\section{Related Services}

Per the IDEA, related services are supportive services that are required for children with disabilities to benefit from special education. According to the Individuals with Disabilities Education Act (IDEA) (34 CFR. § 300.34[a]) as well as the California Department of Education (CDE) (September 13, 2011), related services for special education students with emotional and behavioral needs might include any of the following: a) counseling services, b) parent counseling and training, c) psychological services, d) rehabilitation counseling and e) social work services. 
These specific services are not intended to be exhaustive (CDE, 2011, September 13). The IDEA states explicitly that counseling services (a, b, and c above) can be provided by "...qualified social workers, psychologists, guidance counselors, or other qualified personnel (34 CFR. § $300.34[\mathrm{c}][2]) . "$

The language of the IDEA is echoed in the California Code of Regulation (5 C.C.R. $\S$ 3051.10), where the California Commission on Teacher Credentialing authorizes school psychologists to provide "psychological counseling for individuals, groups, and families." No matter how school districts define mental health services, they are subject to the same legal standards and guidelines as other related services. In other words, all related services, including those for emotional and behavioral needs, support Individualized Education Plan (IEP) goals, which should address unique needs identified in the assessment process.

Special education law (34 CFR. $\S 300.101,300.320$, and 300.324) requires that the IEP team determine what related services, if any, are necessary for children to benefit from special education and that the IEP team must write this determination into the IEP Another way to understand this is that the IEP team must document a clear rationale for providing related services and how those services will help children to benefit from their other special education services (34 CFR. § 300.320[a][7]).

\section{Educationally Related Mental Health Services \& AB 114}

Although the term Educationally Related Mental Health Services (ERMHS) is derived from the language contained in $\mathrm{AB} 114$, the CDE later clarified that "ERMHS" was not a new service but instead meant "related services for students who have emotional and behavioral needs" (CDE, 2012, January 05). Despite this, LEAs and school psychologists continue to use the term ERMHS and similar terms such as ERICS, or "educationally related intensive 
counseling services" to indicate a second, more intense, level of service than what is provided by site-level practitioners. Designated Instructional Services (DIS), a term used in California synonymous with related services, is then subsequently viewed as a separate tier of services when compared to ERMHS or ERICS. Although these terms have the same legal parameters as related services, ERMHS or ERICS routinely require a lengthy 60-day evaluation period. After this drawn-out process, a more intense service, if determined necessary, is often provided by specialists who are presumed to have additional training with mental health services or, in some cases, additional licenses (e.g., LCSW, LPCC, LMFT, Licensed Psychologist).

Unfortunately, in California, establishing DIS counseling and ERMHS or ERICS as two different counseling services clouds the fact that they are both related services and subject to identical legal guidelines. This practice creates a two-tier system (sometimes three tiers) that is wholly a creation of school district policies that do not appear to have a clear basis in law and fall short of recommendation for effective School-based-mental-health-services (SBMHS; Doll et al., 2017).

This distinction seems to be a continuation of the process used by county Departments of Mental Health before AB 114, where County Mental Health Departments often did extensive assessments after receiving a referral from a school district. This approach to structuring mental health services is also different than how other related services are provided. For example, although students may move from receiving more frequent or longer sessions of occupational therapy or speech and language therapy, these services are provided by the same practitioners within the same service delivery system.

Apart from an initial 60-day special education evaluation period, students who might need ERMHS or ERICS often face an additional 60-day assessment timeline before accessing 
these more intensive services when the IEP Team could more simply make this decision after considering extant data. For most other related services, a decision to provide more intense services is based on progress monitoring (i.e., evaluation of goal progress, target behavior reduction, increased use of adaptive replacement skills taught in counseling, etc.) and does not typically require an additional formal assessment. As such, this two-tiered system parts not only from legal precedence, but also from recommended practices that changes in the length, frequency, or intensity of interventions be based on progress monitoring data rather than timeconsuming new formal assessments (Weist et al., 2018).

\section{Assessment and Mental Health Evaluations}

Under current California law, the special education assessment process should consider whether a student's suspected disabilities and unique needs include a mental health component (CDE, 2014, March 21). If data from an initial or triennial reevaluation identifies a need that requires mental health services, the IEP team can provide that service without further evaluation. If a special education evaluation was not comprehensive enough to address this need, it would appear to open school districts up to liability for not assessing in all areas of suspected disability or for failing to identify all the student's unique needs. This position would further part from the IDEA (2004) requirement that the evaluation is "...sufficiently comprehensive to identify all [emphasis added] of the child's special education and related service needs, whether or not commonly linked to the disability category in which the child has been classified" (34 CFR. $\S$ $300.304[\mathrm{c}][6])$.

Further, CA Ed Code 56320 explicitly states that assessment tools:

"(3) Are administered by trained and knowledgeable personnel and are administered in accordance with any instructions provided by the producer of the assessments, except that 
individually administered tests of intellectual or emotional functioning shall be administered by a credentialed school psychologist."

School psychologists are well trained to conduct comprehensive assessments of social, emotional, and behavioral needs, and a thorough assessment conducted by school psychologists typically contains the necessary information to determine the need for mental health services and write IEP goals. In some school districts, additional assessments are conducted by personnel who are not school psychologists but hold a state license for private practice. It is important to remember that these assessments also fall under CA Ed Code 56320. It is also questionable if the additional information provided by these evaluations adds value above that of a comprehensive psychoeducational evaluation conducted by a school psychologist in determining the need for mental health services or developing IEP goals.

Considering the changes stipulated by $\mathrm{AB} 114$, the $\mathrm{CDE}$ stated that "...many policies, procedures, and practices which were in place before $\mathrm{AB} 114$ may no longer be required" (CDE 2011, July 26). In effect, the CDE discussed that $A B 114$ would "...potentially simplify the assessment process in some ways..." by essentially cutting out the sometimes-lengthy evaluations previously encountered by AB 3632 relying on community agencies (CDE, 2014, March 21). Yet, as already indicated, the requirement for additional mental health assessments similar to the prior procedures under $\mathrm{AB} 3632$ is often maintained by local education agencies. Thus, most districts have not simplified systems, which results in long delays for students to receive services.

\section{Recommended practices: Implementing a Case Conceptualization Model}

As discussed above, the underlying confusion around the implementation of AB 114 has led to lengthy formal evaluations that do not appear to be legally required, especially for students 
whose IEPs may already contain sufficient data to determine the need for more intense mental health services. These procedures appear to be an unnecessary barrier for youth with mental health struggles. In addition to delaying the time before services can be provided, our observations suggest that current ERMHS evaluations are often redundant with "ordinary" psychoeducational assessments and do not necessarily provide relevant data to guide treatment and progress monitoring (Arora et al., 2016).

Often these evaluations are guided by the notion that further knowledge about the nature of the student's psychopathology, usually in the form of "accurate diagnoses," will help guide decision making and goal setting. There are several problems with this focus, one being the questionable reliability of many psychiatric diagnoses. For example, a critique of the reliability of the DSM-5 found reliability statistics of only 0.28 for major depressive disorder and only 0.20 for generalized anxiety disorder (Vanheule et al., 2014). These reliability statistics for diagnosing common mood disorders are a little better than chance.

Categorical systems for classifying disorders have also been criticized for lacking treatment validity and utility for guiding treatment selection (Jablensky, 2016; Regier et al., 2013). Although we believe that school psychologists should have a working knowledge of systems like the DSM-5, the notion that this knowledge is critical to determining mental health needs is a misconception. It is also important to note that DSM diagnoses are not required in law for students to receive special education or related services. This is true even for school-based mental health services.

\section{Case Conceptualization}

As an alternative to the practices critiqued above, we recommend the use of case conceptualization. Case conceptualization, also referred to as case formulation, is a process that 
is ongoing both before and during treatment or interventions. It entails the collection, organization, and interpretation of individual and contextual data to provide a comprehensive picture of clients and their strengths and needs, potential explanations or hypotheses for an individual's present psychological, interpersonal, and behavioral challenges, and possible treatments or interventions (Butler, 1998; Dudley, Ingham, Sowerby, \& Freeston, 2015; Easden \& Fletcher, 2020; Liese \& Esterline, 2015). Although case conceptualization may involve gathering further assessment data if needed, it emphasizes organizing and interpreting prior data before deciding if more assessment is required.

The American Psychological Association Presidential Task Force on Evidence-Based Practice (2006) regards case conceptualization as one of the core components of clinical expertise. Additionally, case conceptualization fits well with the NASP practice model and its emphasis on data-based decision making and the use of a problem-solving model (NASP, 2020). As a problem-solving approach, case conceptualization focuses on connecting assessment to treatment, which is often missing from typical special education evaluations, including ERMHS evaluations.

It is essential when creating a case conceptualization to identify problems or symptoms that target the core of an individual's struggles (Christon et al., 2015). The process can be done collaboratively with clients, thus, strengthening the therapeutic alliance (Butler, 1998; Dudley et al., 2015). In behavioral psychology, this has been referred to as keystone behaviors (Barnett et al., 1996). Barnett and colleagues describe keystone behaviors as "...those [behaviors] that, if changed, are likely to positively impact the largest set of other significant behaviors, perceptions, or problem environments" (1996, p. 97). In other words, the focus of treatment should be on those emotions, thoughts, and behaviors that will provide the most benefit to the client. 
Case conceptualization has been described as the backbone of psychotherapy and is promoted by numerous professionals and their organizations (Christon et al., 2015). Across several treatment approaches, case conceptualization has been recognized as an effective way of determining outcomes useful in clinical and research settings (Eells, 2013). Additionally, case conceptualization is transtheoretical and serves different theories or approaches to mental health interventions (Liese \& Esterline, 2015). While theories and method vary in case conceptualization, commonly shared components include (1) identifying primary concerns, or the problem; (2) soliciting information through collaborative efforts to describe the issue and underlying processing; (3) organizing and integrating information; and (4) interpreting synthesized data to guide treatment and inform continued monitoring (Ridley et al., 2017a).

Further development and evaluation continue to inform the use of case conceptualization as an evidence-based practice (Christon et al., 2015; Haynes et al., 2020; Ridley \& Jeffrey, 2017b). Although there is limited research, the utility of case conceptualization is supported by the results of studies that examined its use with behavioral interventions and cognitive behavioral therapy. For example, an analysis of 19 studies that compared pre-intervention functional behavioral assessment (FBA), a type of case conceptualization used with behavioral interventions, with no FBA interventions, found that pre-intervention FBA interventions resulted in larger effect sizes (Hurl, et al., 2016). In another study that involved the analysis of 40 audio recordings of therapists, Gower (2011) used the Collaborative Case Conceptualisation - Rating Scale (CCC-RS) in conjunction with other ratings to investigate the relationship between case conceptualization and client outcomes. Gower found that competence in case conceptualization was positively and significantly correlated with outcomes for clients treated for depression (2011). A limitation of this paper, and others promoting case conceptualization, remains the 
acknowledged lack of empirical studies supporting the use of case conceptualization. Future studies are needed to explore formal case analysis of case conceptualization methods within the IEP process to understand its utility better.

The model we propose here is an adaptation of Liese and Esterline's (2015) model. We have chosen this model because it has features, including concept mapping and a problem grid, that facilitate the development of a case conceptualization by providing visual representations of the nature of clients' problems. We also believe that these visual representations make Lise and Esterline's model more useful in multidisciplinary teams.

Lise and Esterline's (2015) model is described as a tool for working with adults. As part of our adaptation, we suggest a series of questions that allow a school psychologist or a multidisciplinary team to evaluate the information available and determine a decision regarding the appropriateness of school-based mental health services for children. The first steps follow Liese and Esterline's model and begin by building a problem grid (see Table 2), developed early in the assessment or during initial counseling sessions. Through discussion and inquiry, priority problems are identified along with related behaviors, feelings, and thoughts. The second stage involves the counselor conceptualizing the case by developing a concept map (Liese \& Esterline, 2015). A concept map makes connections between different problems and hypothesizing possible explanations (see Figure 1). Liese \& Esterline (2015) describe the process of creating a concept map in four steps:

1. "The client's name is placed in a circle at the center of the concept map, and the client's main problems are plotted around the circle

2. The client's behaviors, feelings, and thoughts are then plotted in circles around the problems associated with them. 
3. The problems are plotted so that problems that have a close connection are put close together.

4. Arrows are used to indicate dynamic relationships between problems, behaviors, feelings, and thoughts" (Liese \& Esterline, 2015, p. 191).

The length of these two initial stages may vary depending on the number, complexity, and severity of problems. These two first stages of the case conceptualization process should involve prior assessment data and other elements of a client's history. If an ongoing case is being used, existing progress monitoring data may support and shape the case. Garry's case presented below, while mostly fabricated, is based on the authors' experiences with students and their everyday struggles related to anxiety, social stress, and academics.

Common recurring themes (Table 2) are noted as well as specific comments (e.g., "I'm afraid I won't succeed") drawn from assessment interviews and initial sessions. In this case, anxiety quickly presents as a definite problem with specific behaviors, feelings, and thoughts. In Garry's case, anxiety is undoubtedly a core problem, but it is essential to also account for other related difficulties such as social withdrawal and academics. The resulting problem grid should be carefully reviewed by the student, the assessors, and appropriate staff (teachers, parents, previous assessments) and sensitively while maintaining sensitivity and confidentiality.

With the development of a strong therapeutic rapport and a thorough understanding of a student's difficulties, the concept map (Figure 1) is used to further visually enhance and review the case with a student. Garry's main problems were plotted in rectangular shapes to establish themes from the problem grid. Surrounding circles are connected to indicate their dynamic relationships with the primary areas of concern. Following Liese and Esterline's (2015) guidelines, this information can be used collaboratively to identify, expand, and process 
problems identified during counseling. For example, stress from Garry's academic difficulties was identified as a significant contributor to his anxiety and subsequent feelings of helplessness, incompetency, and low self-esteem. In turn, these difficulties perpetuated feelings of social anxiety and inferiority in academic settings, creating a cycle of anxiety building on anxiety. Once these steps are completed, we recommend the IEP team consider the following steps and questions:

1. Briefly describe this child without using any words from IDEA, the DSM, or other formal descriptions.

2. Describe any known traumatic experiences - can be acute crises or ongoing long-term stresses that negatively impact development or function.

3. What about the family and this child's social context, including community, family, school, classroom, and other ecological factors are important to consider in figuring out a diagnosis and treatment plan? Include any cultural or broader social influences. Be specific and concrete, i.e., this child and this family.

4. What are the child's strengths, or what areas of functioning are intact? What is the evidence available to support this conclusion?

5. What are the student's limitations or areas of concern and need? What is the available evidence to support these conclusions?

6. How has this student been described using IDEA classifications or DSM diagnoses? What evidence supports these classifications?

7. Given all the information above, considering the student's unique needs, what are the priority areas for support or intervention, and why? 
8. If these needs were to improve, what would be a reasonable outcome? How might these outcomes be assessed or measured?

9. Which of these services would support current IEP goals? How would they be improved?

10. Are new goals necessary to capture the outcome described above? If so, what goals would best achieve this outcome?

11. Is there enough information available to warrant the provision of related services for social, emotional, and behavioral needs?

a. If not, what additional assessment would provide relevant information?

b. If there is enough information, which related services are needed and what unique needs will they support.

\section{Conclusion}

The process described above responds directly to the legal mandates surrounding the provision of related services. In many cases, by gathering useful data and adhering to legal requirements, case conceptualization can eliminate the additional assessments that is often done when IEP teams consider the need for mental health services. Case conceptualization has the potential to provide a more efficient process for the delivery of these services. It will also help the team identify what other information may be necessary if more assessment is recommended, making any further evaluation more focused. Lastly, a case conceptualization process, which will often be based on information already available to an IEP team, will be less intrusive to students and their families, who have often already been subject to time-consuming and extensive evaluations. Although our discussion has focused on the mental health needs of special education students, we also believe that case conceptualization has the potential to benefit all students who need mental health services, including general education students. Although we argue for the 
benefits of case conceptualization as a way of developing a broad picture of students' strengths and needs, we also recommend that future research examine if case conceptualization leads to better outcomes for children.

On behalf of all authors, the corresponding author states that there is no conflict of interest.

\section{Compliance with ethical standards}

This research leading to this paper did not involve gathering data from humans or animals; thus, no informed consent was required. On behalf of all authors, the corresponding author states that there is no conflict of interest. 


\section{References}

A.B. 3632, Chapter 26 (1984).

A.B. 114, Chapter 43. (2011).

Adelman, H. S. \& Taylor, L. (2012). Mental health in schools: Moving in new directions. Contemporary School Psychology, 16, 9-18. http://www.caspwebcasts.org/new/index.php?option=com_content\&view $=$ article $\& \mathrm{id}=51$ \&Itemid $=60$

American Psychiatric Association. (2013). Diagnostic and statistical manual of mental disorders (5th ed.). Author.

American Psychological Association Presidential Task Force on Evidence-Based Practice (2006). Evidence-based practice in psychology. American Psychologist, 61(4), 271-285. https://doi-org/10.1037/0003-066X.61.4.271

Arora, P. G., Connors, E. H., George, M. W., Lyon, A. R., Wolk, C. B., \& Weist, M. D. (2016). Advancing evidence-based assessment in school mental health: Key priorities for an applied research agenda. Clinical Child and Family Psychology Review, 19(4), 271-284. https://doi.org/10.1007/s10567-016-0217-y

Barnett, D., Bauer, A., Ehrhardt, K., Lentz, F., \& Stollar, S. (1996). Keystone targets for change: Planning for widespread positive consequences. School Psychology Quarterly, 11(2), 95117. https://doi.org/10.1037/h0088923

Burns, B. J., Costello, E. J., Angold, A., Tweed, D. Stangl, D., Farmer, E. M., \& Erkanli, A. (1995). Children's mental health service use across service sectors. Health Affairs, 14, 147-159. https://doi.org/10.1377/hlthaff.14.3.147

Butler, G. (1998). Clinical formulation. In A.S. Bellack \& M. Hersen (Eds.), Comprehensive clinical psychology. Pergamon. 
California Commission on Teacher Credentialing. (n.d.). https://www.ctc.ca.gov/docs/defaultsource/leaflets/cl606c.pdf

California Department of Education. (2011, July 26). Assembly Bill 114: Local Educational Agencies' Responsibility for Providing Related Services to Students with Disabilities. https://www.cde.ca.gov/sp/se/ac/ab114memo.asp

California Department of Education. (2011, September 13). Assembly Bill 114: Related Services Under the Individuals with Disabilities Education Act. https://www.cde.ca.gov/sp/se/ac/rltdsrvcidea.asp

California Department of Education (2012, January 05). Assembly Bill 114: Use of mental health funds in the budget act of 2011-12. https://www.cde.ca.gov/sp/se/ac/useofmhfunds.asp

California Department of Education (2014, March 21). Assembly Bill 114: Assessment SummaryRevised. https:/www.cde.ca.gov/sp/se/ac/documents/assessmentsummary.doc

Castillo, J. M., Wolgemuth, J. R., Barclay, C., Mattison, A., Tan, S. Y., Sabnis, S., Brundage, A., \& Marshall, L. (2016). A qualitative study of facilitators and barriers related to comprehensive and integrated school psychological services. Psychology in the Schools, 53(6), 641-658. https://doi.org/10.1002/pits.21932

Christon, L. M., McLeod, B. D., \& Jensen-Doss, A. (2015). Evidence-based assessment meets evidence-based treatment: An approach to science-informed case conceptualization. Cognitive and Behavioral Practice, 22(1), 36-48. https://doi.org/10.1016/j.cbpra.2013.12.004

Committee on School Health (2004). School-based mental health services. Pediatrics, 113(6), 1939-1845. http://pediatrics.aappublications.org/content/113/6/1839 
Cowan, K. C. (2010). The NASP Practice Model: A framework for promoting and implementing a comprehensive role. Communique Online, 39(4).

Dudley, R., Ingham, B., Sowerby, K., \& Freeston, M. (2015). The utility of case formulation in treatment decision making; the effect of experience and expertise. Journal of Behavior Therapy and Experimental Psychiatry, 48, 66-74.

https://doi.org/10.1016/j.jbtep.2015.01.009

Easden, M. H., \& Fletcher, R. B. (2020). Therapist competence in case conceptualization and outcome in CBT for depression. Psychotherapy Research, 30(2), 151.

https://doi.org/10.1080/10503307.2018.1540895

Education Code, 34 C.F.R. $§ 300.34[$ a] (2004). https://sites.ed.gov/idea/

Education Code, 34 C.F.R. $§ 300.34$ [c][2] (2004). https://sites.ed.gov/idea/

Education Code, 34 C.F.R. $§ 300.101$ (2004). https://sites.ed.gov/idea/

Education Code, 34 C.F.R. $§ 300.320$ (2004). https://sites.ed.gov/idea/

Education Code, 34 C.F.R. $§ 300.304$ [c][6] (2004). https://sites.ed.gov/idea/

Education Code, 34 C.F.R. $§ 300.324$ (2004). https://sites.ed.gov/idea/

Education Code, 5 C.C.R. $\S 3051.10$. https://govt.westlaw.com

Eells, T. D. (2013). The case formulation approach to psychotherapy research revisited.

Pragmatic Case Studies in Psychotherapy, 9(4), 426-447.

https://doi.org/10.14713/pcsp.v9i4.1834

Fagan, T. K., \& Wise, P. S. (2000). School Psychology: Past, Present, and Future. Second Edition. NASP Publications. 
Freedman, R., Lewis, D., Michels, R., Pine, D., Schultz, S., Tamminga, C., \& ... Yager, J. (2013). The initial field trials of DSM-5: New blooms and old thorns. American Journal of Psychiatry, 170(1), 1-5. https://doi.org/10.1176/appi.ajp.2012.12091189

Gower, P. (2011). Therapist competence, case conceptualization and therapy outcome in cognitive behavioural therapy (Doctoral dissertation, University of Exeter, Exeter, United Kingdom). https://ore.exeter.ac.uk/repository/handle/10036/3275

Haynes, S. N., O'Brien, W. H., \& Godoy, A. (2020). A proposed model for the psychometric evaluation of clinical case formulations with quantified causal diagrams. Psychological Assessment, 32(6), 541-552. https://doi-org/10.1037/pas0000811

Individuals with Disabilities Education Act, 20 U.S.C. $§ 1400$ (2004). https://sites.ed.gov/idea/ Jablensky, A. (2016). Psychiatric classifications: Validity and utility. World Psychiatry, 15(1), 26-31. https://doi.org/10.1002/wps.20284

Liese, B. S., \& Esterline, K. M. (2015). Concept mapping: A supervision strategy for introducing case conceptualization skills to novice therapists. Psychotherapy, 52(2), 190-194. https://doi.org/10.1037/a0038618

Merrell, K. W., Ervin, R. A., \& Gimpel, G. A. (2006). School psychology for the 21 st century: Foundations and practices. Guilford Press.

National Association of School Psychologists. (2020). The professional standards of the National Association of School Psychologists. https://www.nasponline.org/standards-andcertification

Petereit, T. (2020). An exploration of the alignment of actual and desired roles for school psychologists (Publication No. 27830895). [Doctoral dissertation, University of Nebraska]. ProQuest Dissertations Publishing. 
Regier, A. D., Kuhl, E. A., \& Kupfer, D. J. (2013). The DSM-5: Classification and criteria changes. World Psychiatry, 12(2), 92-98. https://doi.org/10.1002/wps.20050

Ridley, C. R., \& Jeffrey, C. E. (2017a). Thematic mapping in case conceptualization: An introduction to the special section. Journal of Clinical Psychology, 73(4), 353-358. https://doi.org/10.1002/jclp.22355

Ridley, C. R., \& Jeffrey, C. E. (2017b). The conceptual framework of thematic mapping in case conceptualization. Journal of Clinical Psychology, 73(4), 376-392. https://doi.org/10.1002/jclp.22353

Timimi, S. (2014). No more psychiatric labels: Why formal psychiatric diagnostic systems should be abolished. International Journal of Clinical and Health Psychology, 14, 208-215. https://doi.org/10.1016/j.ijchp.2014.03.004

Vanheule, S., Desmet, M., Meganck, R., Inslegers, R., Willemsen, J., De Schryver, M., \& Devisch, I. (2014). Reliability in psychiatric diagnosis with the DSM: Old wine in new barrels. Psychotherapy and Psychosomatics, 83, 313-314. https://doi.org/10.1159/000358809

Wiley, D. C., \& Cory, A. C. (2013). Encyclopedia of school health. SAGE Publications.

Weist, M. D., Eber, L., Horner, R., Splett, J., Putnam, R., Barrett, S., Hoover, S. (2018). Improving Multitiered Systems of Support for Students With “Internalizing” Emotional/Behavioral Problems. Journal of Positive Behavior Interventions, 20(3), 172-184. https://doi.org/10.1177/1098300717753832 
Table 2

Garry's Problem Grid, Including Associated Behaviors, Feelings, and Thoughts

\begin{tabular}{|c|c|c|c|}
\hline Problem & Behaviors & Feelings & Thoughts \\
\hline Anxious & $\begin{array}{l}\text { - Avoiding classes and social } \\
\text { situations } \\
\text { - Struggling to maintain the } \\
\text { pace of classes due to fixating } \\
\text { on assignments being perfect } \\
\text { - Not turning in homework, } \\
\text { perseverating on quality of } \\
\text { work and potential evaluative } \\
\text { situations } \\
\text { - Mild hair pulling } \\
\text { - Frequently apologizing } \\
\text { - Worrying about future }\end{array}$ & 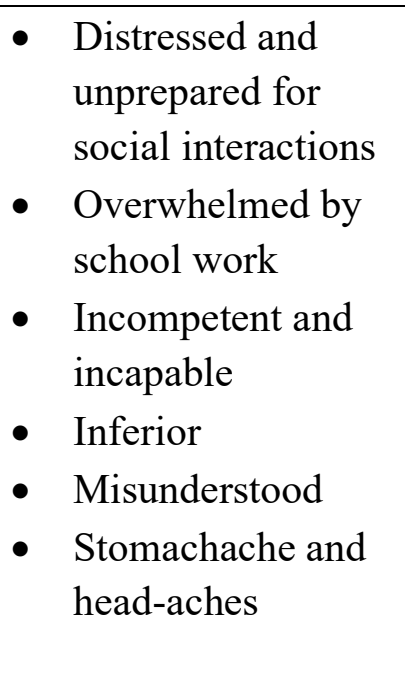 & $\begin{array}{l}\text { - "I'm afraid I } \\
\text { won't succeed" } \\
\text { " "I'm not doing } \\
\text { well, I'm never } \\
\text { going to get } \\
\text { better." } \\
\text { - "I'm just so } \\
\text { worried." } \\
\text { "I'm sorry, } \\
\text { sorry." }\end{array}$ \\
\hline $\begin{array}{l}\text { Social } \\
\text { withdrawal }\end{array}$ & $\begin{array}{l}\text { - Using apathetic and defeating } \\
\text { language } \\
\text { Poor participation in classes } \\
\text { Avoiding difficult tasks or } \\
\text { activities } \\
\text { - Low affect, hanging head, } \\
\text { little eye-contact, walking } \\
\text { slowly }\end{array}$ & $\begin{array}{l}\text { - Feelings of } \\
\text { helplessness } \\
\text { - Feeling } \\
\text { misunderstood and } \\
\text { unsocial } \\
\text { - Negative } \\
\text { assumptions }\end{array}$ & $\begin{array}{l}\text { - "I'm not doing } \\
\text { well." } \\
\text { - "It's not going } \\
\text { to go well." } \\
\text { - "I'll never } \\
\text { make friends." } \\
\text { - "Things are } \\
\text { just getting } \\
\text { worse." }\end{array}$ \\
\hline $\begin{array}{l}\text { Academic } \\
\text { difficulties }\end{array}$ & $\begin{array}{l}\text { - Difficulties focusing on and } \\
\text { tracking in class } \\
\text { - Checking grades frequently } \\
\text { - Losing interest and } \\
\text { motivation }\end{array}$ & $\begin{array}{l}\text { - Overpowered and } \\
\text { too far behind to } \\
\text { catch up } \\
\text { - No matter how } \\
\text { much work, still } \\
\text { feel behind } \\
\text { - Worrying about } \\
\text { future classes }\end{array}$ & $\begin{array}{l}\text { - "I'm not } \\
\text { smart." } \\
\text { - } \quad \text { "Oh my gosh, I } \\
\text { hate this } \\
\text { [history] class." } \\
\text { - "I'm trying my } \\
\text { hardest." }\end{array}$ \\
\hline
\end{tabular}

Note. Adapted from Liese \& Esterline, 2015, p. 191 


\section{Figure 1}

Concept mapping for a hypothetical student, Garry, who is struggling with anxiety, academic difficulties, and social withdrawal.

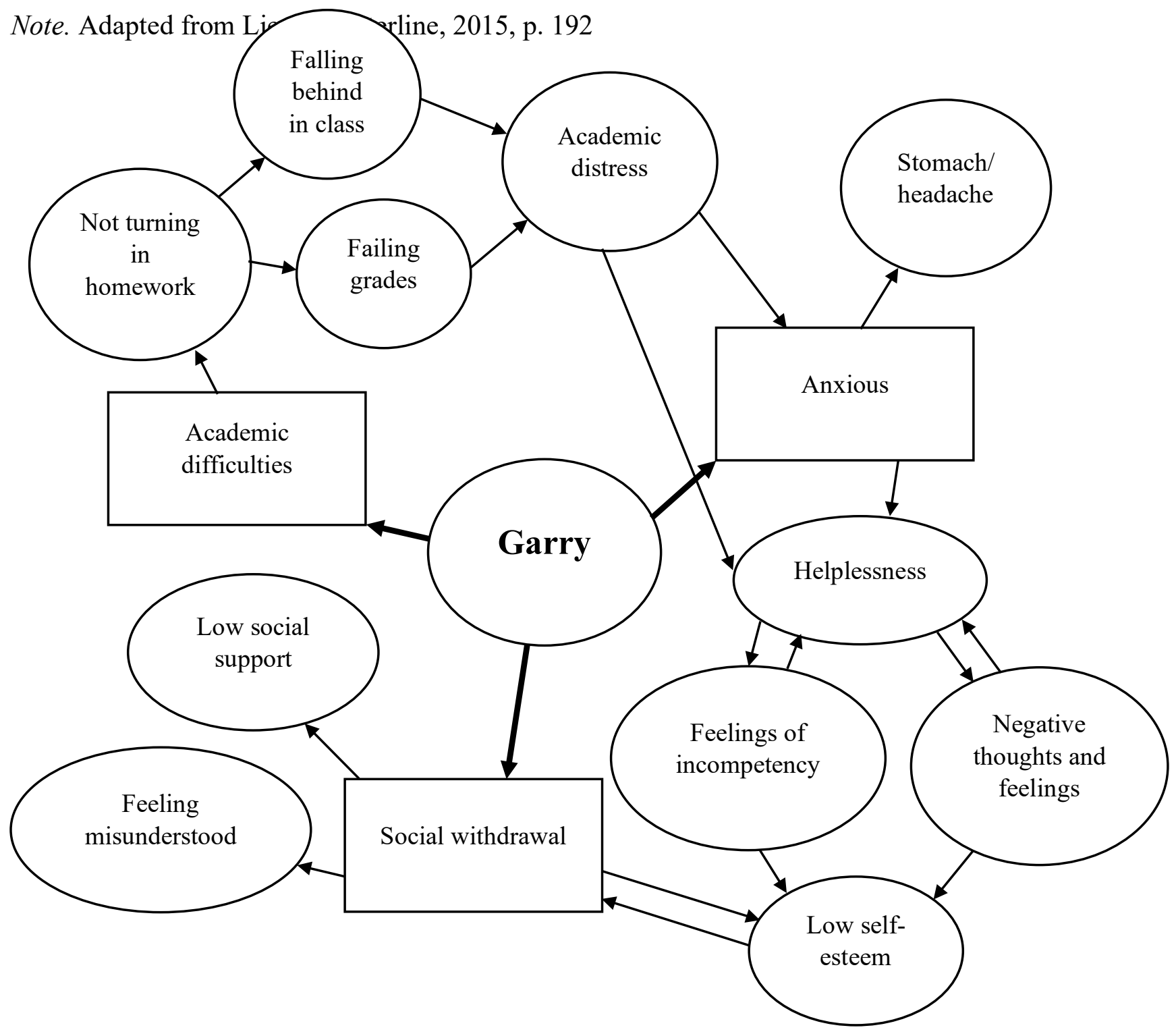

